\title{
Sexualidade na Terceira Idade: as Representações sobre Sexo
}

\author{
Renara Meira Gomes ${ }^{1}$; Joserlane Meira Cidreira ${ }^{1}$; Maria da Conceição Quirino dos Santos ${ }^{2}$; \\ Norma Lopes de Magalhães Velasco Bastos ${ }^{3}$; Kay Amparo Santos ${ }^{4}$; Maria Lucia Quirino dos Santos ${ }^{5}$
}

\begin{abstract}
Resumo: Objetivo geral: orientar os idosos quanto à prática sexual segura enfatizando a necessidade de expor suas dúvidas relacionadas à sexualidade, com base em evidências científicas; identificar as representações sobre sexo no processo do envelhecimento, descritas nas publicações científicas nacionais, na sexualidade na terceira idade. Método: trata-se de uma revisão integrativa, na operacionalização dessa revisão, utilizaram-se as seguintes etapas: delimitação do objetivo; definição dos critérios de inclusão das produções científicas; busca dos estudos nas bases de dados; análise dos resumos dos estudos; seleção dos estudos, de acordo com os critérios de inclusão; avaliação criteriosa e fichamento dos estudos selecionados e, por fim, a análise dos dados. Conclusão: o estudo apontou que os Enfermeiros tem um papel importante em relação à sexualidade do idoso, pois o mesmo vem colaborar para uma qualidade de vida saudável.
\end{abstract}

Descritores: Envelhecimento; Sexualidade na Terceira Idade; Enfermeiros.

\section{Sexuality in Old Age: The Representations about Sex}

\begin{abstract}
General objective: to guide the elderly how to practice safe sexual emphasizing the need to expose your questions related to sexuality, based on scientific evidence; Identify the representations about sex in the aging process, described in the national scientific publications on sexuality in old age. Method: an integrative review, on operationalization of this review, using the following steps: definition of the goal; definition of the criteria for inclusion of scientific productions; search for studies in databases; analysis of the abstracts of the studies; selection of the studies, according to the inclusion criteria; careful assessment and booking of selected studies and, finally, the analysis of the data. Conclusion: the study pointed out that the Nurses have an important role in relation to the sexuality of the elderly, because it comes to a healthy quality of life.
\end{abstract}

Words keys: Aging, sexuality in old age, nurses.

\footnotetext{
${ }^{1}$ Graduandas em Enfermagem pela Faculdade de Tecnologia e Ciências de Jequié/Bahia. Brasil. E-mail: nara_rhema@hotmail.com.

${ }^{2}$ Enfermeira, Doutoranda especial em Enfermagem e Saúde, Mestre em Terapia Intensiva, Professora da Faculdade de Tecnologia e Ciências de Jequié/BA. Brasil. E-mail: conceicaoquirino@gmail.com.

${ }^{3}$ Enfermeira, Mestre em Terapia Intensiva, Professora Plena departamento de Saúde II, Universidade Estadual do Sudoeste da Bahia/UESB. Jequié/BA, Brasil. E-mail: normademagalhaes@gmail.com.

${ }^{4}$ Enfermeira. Mestranda em Enfermagem e Saúde. Professora da Faculdade de Tecnologia e Ciências/FTC. Jequié (BA) Brasil. E-mail: kayamparo@ hotmail.com.

${ }^{5}$ Enfermeira. Sanitarista. Professora da Faculdade de Tecnologia e Ciencias/FTC. Jequié (BA). Brasil. E-mail: luciakirino@hotmail.com.

Autor correspondente: Renara Meira Gomes. Rua Isaías Rêgo, 30, Centro. Dário Meira/BA. E-mail: nara_rhema@hotmail.com
} 


\section{Introdução}

O conceito de envelhecimento há alguns anos atrás erroneamente era considerado patológico, este conceito atrapalhava os avanços científicos na área da geriatria e gerontologia. Na contemporaneidade a velhice é uma construção social. A gerontologia é o ramo da medicina que se dedica ao idoso e suas doenças e a gerontologia estuda o envelhecimento para uma boa qualidade de vida.

Uma das mudanças mundiais em relação ao envelhecimento é a qualidade de vida da população idosa presente em nossa sociedade que vem aumentando de maneira acelerada, por esta razão é necessário pensar na implementação ainda das Políticas Públicas de grande alcance para abraçar esta nova demanda populacional.

Atualmente uma das maiores inquietações sobre o envelhecimento da população idosa, caracteriza a melhoria da qualidade de vida. Nesta perspectiva a pesquisa estuda a pessoa idosa como sujeito de direito em virtude dos avanços científicos que aumenta a expectativa de vida desta população sendo internacionalmente conhecidos. Assim o envelhecimento é algo que motiva agitações na Política de Saúde Pública, pois tem dificuldades em dar conta do número crescente da população idosa.

As estimativas brasileiras fazem seu prenúncio de que até 2025 o Brasil será o sexto país do mundo com maior número de pessoas idosas segundo a Organização Mundial da Saúde (OMS). Atualmente o conceito de envelhecimento segundo a Organização Mundial da Saúde adotou o termo de envelhecimento ativo e envelhecimento para expressar o processo de conquistas dessa visão.

Partido da teoria, a sexualidade na terceira idade é um tabu, ou seja, é algo particular só para os jovens, deste modo exclui os idoso das vivências afetivas e sexuais traz problemas para uma boa qualidade de vida.

Assim é importante lembrar que a sexualidade é vital para o ser humano a mesma é a continuação do indivíduo o sexo é a termologia tanto do sexo feminino como masculino, ou seja, a intimidade da efetividade com o outro. Hoje já se sabe que o interesse pelo sexo é normal em toda a idade, mas na sociedade a sexualidade e vista normal para os jovens e libertinagem para os idosos. Por isso a sexualidade na terceira idade é mais que ato sexual é carinho e fantasia, amor e inteligência. 
O Estatuto do Idoso em seus artigos asseguram aos idosos a qualidade de vida fator primordial para a sexualidade na terceira idade, ou seja, quanto maior for ativo o idoso sua satisfação imediatamente contribuirá para uma excelente qualidade de vida.

Todavia, o sexo em qualquer idade precisa de proteção e alerta sobre o aumento de doenças sexualmente transmissíveis em idosos. O ser humano passa por várias modificações em seu corpo com o decorrer do tempo, e ao chegar à senescência surgem limitações físicas e mudanças estéticas, fazendo com que as pessoas pensem nos idosos como menos sedutores e sensuais. Talvez, por esse e outros motivos, os idosos tenham dificuldades em expressar sua sexualidade (COELHO et al, 2010).

Logo é fato que não existem limites de idade para conservar uma atividade sexual mesmo com mudanças fisiológica. A sexualidade é uma forma de expressividade afetiva e o desejo do sexo não termina com a idade.

Estudos realizados sobre a sexualidade dos idosos relatam que a sexualidade tanto dos idosos como dos jovens iniciam desde o nascimento até o momento da morte. Os mesmos não podem ser esquecidos por profissionais da Saúde e nem mesmo pela sociedade os mesmos deverão ser trabalhados nas academias os valores e as atitudes em relação à temática para que venha futuramente com as novas gerações ter uma qualidade de vida satisfatória.

Diante do tema exposto, os Enfermeiros tem um papel importante em relação a sexualidade do idoso, pois o mesmo vem colaborar para uma qualidade de vida saudável. A atuação dos Enfermeiros é uma ação de cumplicidade e diálogo, sem menosprezo e preconceito, no sentido de compreensão e escuta da problemática do idoso, para que juntos construam estratégias que despertem seus desejos (COELHO al. 2010).

Nessa perspectiva o presente objeto de pesquisa pretende enquanto questão norteadora saber de que forma as representações sobre sexo estão intrínsecas no processo do envelhecimento ativo?

Para iniciarmos esta parte do trabalho de Conclusão de Curso, é necessário que discutamos dois temas: Sexualidade na Terceira Idade e as Representações Sociais. Em seguida abordaremos A Sexualidade e o Enfermeiro atuante importante na promoção da saúde. O interesse de realizar este estudo surgiu do próprio cotidiano o qual se percebe distintas manifestações sobre as representações sociais, entre elas o preconceito.

Assim, definiu-se como objetivo temático Identificar as representações sobre sexo no processo do envelhecimento, descritas nas publicações científicas nacionais, na sexualidade na 
terceira idade; Assim como Analisar as evidências científicas que abordam os fatores que interferem na sexualidade de idosos, em meio às representações sobre sexo.

\section{O envelhecimento no Brasil}

Não há como falar de envelhecimento da população idosa sem antes citar seu conceito, atualmente o envelhecimento segundo a Organização Mundial da Saúde adotou o termo de envelhecimento ativo para expressar o processo de conquistas dessa visão.

O que é envelhecimento ativo? É o processo de otimização das oportunidades de saúde, participação e segurança, com o objetivo de melhorar a qualidade de vida à medida que a pessoa fica mais velhas. Uma das mudanças mundiais em relação ao envelhecimento é a qualidade de vida da população idosa presente em nossa sociedade que vem aumentando de maneira acelerada, por esta razão é necessário pensarmos ainda em Políticas Públicas de grande alcance para abraçar esta nova demanda populacional.

Atualmente uma das maiores inquietações sobre o envelhecimento da população idosa caracteriza a melhoria da qualidade de vida. Nesta perspectiva a pesquisa estuda a pessoa idosa como sujeito de direito em virtude dos avanços científicos que aumenta a expectativa de vida desta população sendo internacionalmente conhecidos.

Assim o envelhecimento é algo que motiva agitações na Política de Saúde Pública, pois tem dificuldades em dar conta do número crescente da população idosa. As estimativas brasileiras fazem seu prenúncio de que até 2025 o Brasil será o sex to pais do mundo com maior número de pessoas idosas segundo a Organização Mundial da Saúde (OMS).

É comum deparar com vários preconceitos em relação ao que dizem respeito à vida humana. Por isso a Constituição Federal de 1988 e a Política Nacional do Idoso (PNI) têm como objetivo promover a longevidade com qualidade de vida para todas as idades impedindo qualquer forma de discriminação para os idosos por ser o modificador desta política; assim consiste a diretriz da Política Nacional do Idoso que asseguram os relatos citados: Artigo $4^{\circ}$ Viabilização de formas alternativas de participação, ocupação e convívio do idoso, que proporcionem sua integração às demais gerações. O Estatuto do Idoso vem consolidar esta política assegurando ao idoso os direitos pertinentes a sua faixa etária (BRASIL, 2006). 
O Estatuto do Idoso em seus artigos asseguram aos idosos a qualidade de vida fator primordial para a sexualidade na terceira idade, ou seja, quanto maior for ativo o idoso sua satisfação imediatamente contribuirá para uma excelente qualidade de vida.

Ainda convém lembrar que o Estatuto do Idoso no Art. $8^{\circ}$ ressalta que o "Envelhecimento é um direito personalíssimo e a sua proteção um direito social, nos termos desta Lei e da Legislação Vigente". E o Art. $9^{\circ}$ relata que é obrigação do Estado garantir à pessoa idosa a proteção à vida e à saúde mediante efetivação de políticas sociais públicas que permitam um envelhecimento saudável e em condições de dignidade.

O envelhecimento é um processo de experiência que conquistamos ao longo dos anos enriquece a vida do ser humano e as que com ele convivem; de forma que a sabedoria e os conhecimentos adquiridos proporciona-lhe potenciais que o torna capaz de tomar decisões sobre vários aspectos da vida, assim, garantir a dignidade da pessoa humana é essencial para que se alcance o fim social desejável e um verdadeiro Estado de Direito.

\section{A Sexualidade e o envelhecimento}

Partido da teoria, a sexualidade na terceira idade é um tabu, ou seja, é algo particular só para os jovens, deste modo excluir os idosos das vivências afetivas e sexuais traz problemas para uma boa qualidade de vida. Assim é importante lembrar que a sexualidade é essencial para o todos os seres humanos; à mesma é a continuação do indivíduo o sexo é a nomenclatura tanto do sexo feminino como masculino, ou seja, a intimidade da afetividade com o outro.

Hoje já se sabe que o interesse pelo sexo é normal em todas as idades, mas na sociedade a sexualidade e vista normal para os jovens e libertinagem para os idosos. Por isso a sexualidade na terceira idade é mais que ato sexual é carinho e fantasia, amor e inteligência.

Todavia, o sexo em qualquer idade precisa de proteção e alerta sobre o aumento de doenças sexualmente transmissíveis em idosos. O ser humano passa por várias modificações em seu corpo com o decorrer do tempo, e ao chegar à senescência surgem limitações físicas e mudanças estéticas, fazendo com que as pessoas pensem nos idosos como menos sedutores e sensuais.

Talvez, por esse e outros motivos, os idosos tenham dificuldades em expressar sua sexualidade (COELHO et al, 2010). Porém é fato que não existem limites de idade para 
conservar uma atividade sexual mesmo com mudanças fisiológica. A sexualidade é uma forma de expressividade afetiva e o desejo do sexo não termina com a idade.

Para abrangermos a sexualidade do idoso, é preciso levar em conta que o comportamento sexual é marcante por vários princípios: cultura, religião, e educação são valores que influenciam intensamente o desenvolvimento sexual.

Segundo a definição de sexualidade proposta pela OMS é a "energia que nos leva a procurar amor, contato, ternura e intimidade, que se integra na forma como nos sentimos, moveram, tocamos e somos tocados; é ser-se sensual e ao mesmo tempo sensual, ela influencia pensamentos, sentimentos, ações e interações e por isso influencia a nossa saúde física mental".

Historicamente, a sexualidade durante o envelhecimento foi negada a partir de normas socioculturais que dificultam a experiência sexual na velhice (CEZAR, 2011; FERNANDES, 2010).

Uma pesquisa feita recentemente pela Datafolha online informa que $47 \%$ dos idosos brasileiros fazem sexo regulamente esta notícia tem um significado importantíssimo, pois colabora com autoestima e qualidade de vida. O poeta Vinícius de Moraes em um de seus verso resume que caminhamos inexoravelmente para a morte, ou seja, "a gente mal nasce começa a morrer".

Diante dos três conceitos expostos, observamos que a sociedade aliena e exclui o idoso, mas ao mesmo tempo busca sanar este problema mostrando que o idoso é importante para a sociedade e que requer atenção.

Portanto os idosos estão mais conscientes de seus direitos e compreendem que não podem ser privado do exercício de uma vida saudável e de sua sexualidade em razão da idade

\section{A sexualidade do idoso e a atuação do enfermeiro}

Não há como falar de qualquer atuação do enfermeiro sem antes conceituar o Termo Enfermagem. A Enfermagem é uma profissão comprometida com a saúde do ser humano e da coletividade. Atua na promoção, proteção, recuperação da saúde e reabilitação das pessoas, respeitando os preceitos éticos legais (BRASIL, Lei 5.905/73).

Percebe-se deste modo, que este princípio e a ênfase no respeito aos direitos humanos. E, o marco inicial para que o profissional de enfermagem possa respeitar a vida, a dignidade e 
os direitos humanos o mesmo tem a obrigação de cuidar da saúde e qualidade de vida individual e coletiva do idoso.

A atuação do Enfermeiro é uma ação de cumplicidade e diálogo, sem menosprezo e preconceitos, no sentido de compreensão e escuta da problemática do idoso, para que juntos construam estratégias que despertam seus desejos. (COELHO et al .2010).

Percebemos assim, que a Lei 5.905/73, vem para firma à garantia e a continuidade da assistência de enfermagem como está exposto no Art. 25 desta lei. Desta forma, o enfermeiro deve atuar estimulando o autocuidado que é o princípio fundamental na mudança de vida e na saúde informando que a própria pessoa é o centro de qualquer mudança, pois a pessoa é que conhece sua própria situação sabe o que necessita para se sentir bem.

Portanto o enfermeiro na atenção primaria à saúde tem um amplo espaço de desenvolvimento para seu desempenho profissional voltada para a pessoa idosa como: Consulta de enfermagem, no consultório, domicílio, atividades de educação em saúde individual e coletivo assistencial.

Ainda convém lembrar, que atualmente o termo sexualidade é discorrido na sociedade, porém sobre a prática sexual homem e mulher no processo de envelhecimento pouco são discutidas e às vezes ignoradas pelos profissionais pelo motivo de que a atenção à saúde focaliza a questão da queixa ou doenças.

\section{Metodologia}

Trata-se de uma revisão integrativa, método que tem como finalidade sintetizar as pesquisas publicadas, para obter novas conclusões a partir de um tema de interesse. Na operacionalização dessa revisão, utilizaram-se as seguintes etapas: delimitação do objetivo; definição dos critérios de inclusão das produções científicas; busca dos estudos nas bases de dados; análise dos resumos dos estudos; seleção dos estudos, de acordo com os critérios de inclusão; avaliação criteriosa e fichamento dos estudos selecionados e, por fim, a análise dos dados.

Após a definição do objetivo do estudo, prosseguiu-se com a etapa de levantamento bibliográfico, em todas as bases de dados da Biblioteca Virtual em Saúde, na base de dados da 
LILACS, no período de 2010 a 2015, utilizando as seguintes combinações de descritores: envelhecimento, sexualidade, gênero, representações sociais.

Para melhor fichamento das publicações, a pesquisa teve como critério de inclusão: possuir os descritores destacados no parágrafo anterior, estar na base de dados da BVS, base de artigos apenas em português, bases de acessos gratuitos, textos completos disponíveis. Desde modo, o artigo retrata como critério de exclusão: artigos que incluam HIV/AIDS no tema. Foram encontradas 279 publicações. A partir da leitura exploratória dos resumos desses materiais bibliográficos encontrados, foram selecionadas 213 em português, sendo apenas 55 com base no tema proposto e combinações dos descritores, porém analisando criteriosamente as publicações que retratam sobre o tema, porém de acordo com os critérios de inclusão, chegou-se a $\mathbf{1 1}$ artigos selecionados.

Após o acesso aos textos completos desses 11 estudos, os mesmos foram lidos na íntegra. Assim, após esse procedimento, sete produções científicas foram selecionadas para compor a presente revisão integrativa. Um desses artigos possuía ênfase em cuidador e demência do cônjuge, descritores que o manteve fora da seleção. A pesquisa foi finalizada com isso seis artigos, por entender que esses artigos passaram pela vislumbra do prelo somam ao objeto de estudo desse trabalho, destacando que apenas esse quantitativo possuía o texto com referência ao trabalho que foi proposto pesquisar, sendo esse um dos critérios de inclusão da pesquisa. Os artigos foram identificados com números sequenciais de um a seis no fichamento.

Posteriormente, esses artigos passaram por uma avaliação criteriosa, de modo a compor um fechamento baseado no instrumento de coleta de dados que conteve as seguintes questões: identificação numérica do artigo; citação do artigo; autores; ano de publicação; objetivo(s); resultados apresentados relativos às experiências vivenciadas; e conclusão dos trabalhos.

Foi utilizada a análise qualitativa, desenvolvida por meio da leitura analítica, seguindo as etapas de: análise textual, realizada a partir da leitura cuidadosa dos artigos, obtendo-se uma visão mais abrangente dos dados; análise temática, buscando esclarecimentos a respeito do tema abordado; e análise interpretativa, na qual se desenrolou a problematização dos achados.

A construção da revisão integrativa é constituída por seis etapas, sendo ela: identificação do tema e seleção da hipótese ou questão de pesquisa para elaboração da revisão integrativa; estabelecimento de critérios para inclusão exclusão de estudos/amostragem ou busca na literatura; definição das informações a serem extraídas dos estudos selecionados/categorização dos estudos; avaliação dos estudos incluídos na revisão integrativa; interpretação dos 
resultados; apresentação da revisão/síntese do conhecimento (MENDES; SILVEIRA; GALVÃO, 2008).

Os dados foram apresentados por meio de Quadro, obedecendo uma ordem cronológica crescente de publicação (Quadro I).

Quadro I: Amostra dos artigos que compuseram a análise neste estudo.

\begin{tabular}{|c|c|c|c|c|c|c|}
\hline $\mathbf{N}^{\mathbf{0}}$ & $\begin{array}{c}\text { NOME DO } \\
\text { ARTIGO }\end{array}$ & AUTORES & ANO & $\begin{array}{c}\text { OBJETIVO DO } \\
\text { ESTUDO }\end{array}$ & RESULTADOS & CONCLUSÃO \\
\hline 01 & $\begin{array}{c}\text { Percepção } \\
\text { de mulheres } \\
\text { idosas sobre } \\
\text { sexualidade: } \\
\text { implicações } \\
\text { de } \\
\text { Gênero e no } \\
\text { cuidado de } \\
\text { enfermagem }\end{array}$ & $\begin{array}{l}\text { COELHO } \\
\text { et al. }\end{array}$ & 2010 & $\begin{array}{c}\text { Apresenta a } \\
\text { percepção de } \\
\text { mulheres idosas } \\
\text { sobre sua } \\
\text { sexualidade e analisa } \\
\text { as implicações de } \\
\text { gênero no } \\
\text { envelhecimento } \\
\text { feminino e no } \\
\text { cuidado de } \\
\text { enfermagem. } \\
\end{array}$ & $\begin{array}{c}\text { Os dados foram } \\
\text { analisados em três } \\
\text { categorias: maternidade; } \\
\text { além do sexo; namora } \\
\text { companheirismo. A } \\
\text { análise de discursão de } \\
\text { dados realizou em dois } \\
\text { momentos em primeiro } \\
\text { apresentou-se os dados e } \\
\text { o segundo emergidos das } \\
\text { entrevistas }\end{array}$ & $\begin{array}{c}\text { As mulheres } \\
\text { demonstram } \\
\text { dificuldade em } \\
\text { expressar sua } \\
\text { sexualidade } \\
\text { vivenciando conflitos } \\
\text { com relação sexual e } \\
\text { sexualidade. }\end{array}$ \\
\hline 02 & $\begin{array}{l}\text { Companheir } \\
\text { ismo e } \\
\text { sexualidade } \\
\text { de casais na } \\
\text { melhor } \\
\text { idade: } \\
\text { cuidando do } \\
\text { casal idoso } \\
\end{array}$ & $\begin{array}{l}\text { MORAES } \\
\text { et al. }\end{array}$ & 2011 & $\begin{array}{c}\text { O principal objetivo } \\
\text { é abarcar } \\
\text { desenvolvimento da } \\
\text { sexualidade de um } \\
\text { casal principalmente } \\
\text { como o casal } \\
\text { vivencia sua } \\
\text { sexualidade. }\end{array}$ & $\begin{array}{c}\text { Foi comprovada uma } \\
\text { diminuição no padrão da } \\
\text { atividade sexual, além do } \\
\text { preconceito em relação à } \\
\text { manifestação de carinho } \\
\text { entre os gerontes e o } \\
\text { fortalecimento do } \\
\text { vínculo afetivo com o } \\
\text { passar dos anos. }\end{array}$ & $\begin{array}{l}\text { Resultado final da } \\
\text { pesquisa foi } \\
\text { detectado que há } \\
\text { amor no } \\
\text { relacionamento do } \\
\text { casal, respeito, } \\
\text { cumplicidade. }\end{array}$ \\
\hline 03 & $\begin{array}{l}\text { Satisfação } \\
\text { Sexual entre } \\
\text { Homens } \\
\text { Idosos } \\
\text { Usuários da } \\
\text { Atenção } \\
\text { Primária }\end{array}$ & $\begin{array}{c}\text { LIMA e } \\
\text { SILVA et al. }\end{array}$ & 2012 & $\begin{array}{c}\text { Investigar a } \\
\text { satisfação sexual } \\
\text { entre homens idosos } \\
\text { usuários da } \\
\text { Estratégia de Saúde } \\
\text { da Família do } \\
\text { Recife. }\end{array}$ & $\begin{array}{l}\text { A maior parte dos } \\
\text { entrevistados reside com } \\
\text { a companheira, destes } \\
89,7 \% \text { consideram esse } \\
\text { relacionamento como } \\
\text { bom ou ótimo. }\end{array}$ & $\begin{array}{c}\text { A sexualidade } \\
\text { continua presente na } \\
\text { vida dos homens } \\
\text { maiores de } 60 \text { anos.A } \\
\text { vivência da } \\
\text { sexualidade tem } \\
\text { caráter plural e assim } \\
\text { deve ser encarada } \\
\text { pela sociedade e pela } \\
\text { Equipe da Saúde da } \\
\text { Família. }\end{array}$ \\
\hline 04 & $\begin{array}{c}\text { Representaç } \\
\text { ões sociais } \\
\text { da } \\
\text { sexualidade } \\
\text { entre idosos }\end{array}$ & $\begin{array}{l}\text { QUEIROZ } \\
\text { et al. }\end{array}$ & 2015 & $\begin{array}{l}\text { Conhecer as } \\
\text { representações } \\
\text { sociais sobre a } \\
\text { sexualidade do } \\
\text { Idosos com base na } \\
\text { Teoria das } \\
\text { Representações } \\
\text { Sociais. }\end{array}$ & $\begin{array}{l}\text { Foram entrevistados } 30 \\
\text { idosos, } 23 \text { do sexo } \\
\text { feminino e sete do } \\
\text { masculino. Em relação } \\
\text { ao estado civil, } 21 \text { eram } \\
\text { casados, seis estavam } \\
\text { viúvos e } \\
\text { três encontravam-se } \\
\text { solteiros. Dentre estes, } \\
\text { houve resultado } \\
\text { equitativo a respeito da } \\
\text { religião adotada: } 15 \\
\text { denominaram-se }\end{array}$ & $\begin{array}{l}\text { Amor, respeito e } \\
\text { carinho foram } \\
\text { apontados como } \\
\text { elemento centrais que } \\
\text { estruturavam } \\
\text { reorganizavam a } \\
\text { representação social } \\
\text { da sexualidade na } \\
\text { terceira idade pelo } \\
\text { grupo estudado }\end{array}$ \\
\hline
\end{tabular}




\begin{tabular}{|c|c|c|c|c|c|c|}
\hline & & & & & $\begin{array}{l}\text { católicos e } 15 \\
\text { evangélicos. }\end{array}$ & \\
\hline 05 & $\begin{array}{l}\text { Sexualidade } \\
\text { da mulher } \\
\text { idosa }\end{array}$ & $\begin{array}{c}\text { JUNQUEI- } \\
\text { RA et al. }\end{array}$ & 2015 & $\begin{array}{l}\text { O objetivo deste } \\
\text { artigo é discutir o } \\
\text { impacto da transição } \\
\text { psicossocial } \\
\text { característica do } \\
\text { processo de } \\
\text { envelhecimento } \\
\text { sobre a função } \\
\text { sexual feminina. }\end{array}$ & $\begin{array}{l}\text { Torna-se mais relevante } \\
\text { pela associação } \\
\text { entre satisfação com a } \\
\text { firmeza da ereção e } \\
\text { satisfação com a } \\
\text { vida sexual, o amor e o } \\
\text { romance, além da saúde } \\
\text { geral. }\end{array}$ & $\begin{array}{c}\text { Identificar } \\
\text { peculiaridades da } \\
\text { atividade sexual } \\
\text { nessa população } \\
\text { auxilia a atenção de } \\
\text { profissionais de saúde } \\
\text { aos fatores } \\
\text { psicossociais } \\
\text { envolvidos no } \\
\text { comprometimento } \\
\text { do envelhecimento. }\end{array}$ \\
\hline 06 & $\begin{array}{l}\text { Vovô e } \\
\text { vovó } \\
\text { também } \\
\text { amam: } \\
\text { sexualidade } \\
\text { na terceira } \\
\text { idade }\end{array}$ & CUNHA et al. & 2015 & $\begin{array}{l}\text { Analisar a prática } \\
\text { profissional de } \\
\text { médicos e } \\
\text { enfermeiros da } \\
\text { Estratégia Saúde da } \\
\text { Família no que se } \\
\text { refere a sexualidade } \\
\text { do idoso. }\end{array}$ & $\begin{array}{l}\text { Os resultados revelam o } \\
\text { significado atribuído } \\
\text { pelos profissionais à } \\
\text { sexualidade na terceira } \\
\text { idade. }\end{array}$ & $\begin{array}{l}\text { Constatou-se que o } \\
\text { tema era de difícil } \\
\text { abordagem durante as } \\
\text { consultas, embora } \\
\text { relevante ao contexto. }\end{array}$ \\
\hline
\end{tabular}

Fonte: Artigos pré-selecionados pelo autor.

\section{Resultados}

O primeiro artigo realiza uma análise elaborada por uma equipe de Enfermeiras sendo três doutoras e uma especialista de várias áreas de atuação. A metodologia aplicada foi observação participante, utilizando entrevistas semiestruturadas gerando três categorias: Maternidade; Envelhecimento; Sexualidade e gênero.

A abordagem é qualitativa delimitando a percepção e a vivência de mulheres idosas sobre sua sexualidade. O mesmo tem como objetivo apresentar como as mulheres com mais de 60 anos veem e sentem o desenvolvimento de sua sexualidade, sendo primordial o olhar do enfermeiro cuidador.

A Maternidade enquanto categoria do estudo as mulheres relacionaram quanto ao papel de mãe. A responsabilidade e os problemas encarados tanto pela maternidade, quanto pela criação dos filhos. As gravidezes são rituais de passagem da vida de adolescentes para a vida adulta. A sexualidade aqui fica confundida com a fertilidade, então se supõe que ao deixar de ter filhos deixam também de sentir desejos. 
A categoria do Envelhecimento: vivenciando mudanças e desafios, traz os mais diversos problemas que com o passar dos tempos vai-se adquirindo, tais como: biológico; mental; psicossocial.

A mulher abranda seu interesse em praticar sexo e mostrar sua sexualidade. Neste texto a maioria das idosas retrata o corpo, na questão da estética. $\mathrm{O}$ aparecimento dos primeiros sinais de envelhecimento tais como: rugas, ou mesmo, diminuição da libido, pele ressecada.

A terceira e última categoria Além do sexo: o namoro e o companheirismo, todas sem exceção foram categóricas ao afirmar que o ‘namoro e o companheirismo’ substitui o sexo. Não se mostravam infelizes, pois dizia que beijar bastante, fazer carinhos é tão bom quanto a prática sexual.

Conclui-se que as mulheres mesmo demonstrando dificuldade em expressar sua sexualidade, sendo complexa a temática, expõe que a educação repressora, com valores morais rígidos foi determinante para a construção da identidade social. Estas mulheres que se adaptam aos prazeres possíveis do corpo na velhice tão recentemente vivenciada.

O segundo texto volta-se para um estudo de caso. O qual traz subsídio sobre a experiência de um casal de pessoas idosas. A abordagem tem cunho qualitativo. E o principal objetivo é compreender a sexualidade de um casal de idosos, levando em consideração principalmente como o casal vivencia a sua sexualidade.

Neste ‘estudo de caso’ é referenciada a Teoria do Cuidado Transpessoal (TCT) de Jean Watson na qual a profissão de enfermagem é a protagonista para recuperação e promover a melhoria da saúde, neste 'caso' do ser idoso, mediante a visão holística contribuindo para a qualidade de vida de maneira interpessoal. Na TCT há a defesa do enfoque humanístico no ato de cuidar, tendo como elementos fundamentais: "fatores de cuidado, relações interpessoais de cuidado, e momento/ocasião do cuidado" (Watson, in: JESUS, 2013).

Ainda neste estudo há uma necessidade de visão Transpessoal do Ser, "consciência e intencionalidade para cuidar e promover a cura consciência do cuidado como energia do campo ambiental, consciência fenomenológica e modalidades avançadas de cuidado-cura".

Como resultado na pesquisa foi configurado que há amor no relacionamento do casal, respeito, cumplicidade. Quanto ao ato sexual em si, com penetração, há uma diminuição natural na frequência dos mesmos. Os maiores entraves e barreiras se dão principalmente quanto ao preconceito de que: idoso não sente desejo nem faz sexo. Mas primordial se faz relatar o foi 
externado como a constância de carinho, afagos, respeito o que consolida os laços afetivos dos dois.

A produção textual três foi elaborada por uma equipe interdisciplinar com um mestre e cinco doutores nas diversas áreas, nutricionista, psicóloga, economista e odontólogo. Trata-se de uma abordagem quantitativa realizada na cidade do Recife/PE.

O objetivo do texto se voltou para a satisfação sexual do homem com mais de 60 anos de idade. Sendo desenvolvida a pesquisa com usuários/frequentadores do programa Estratégia Saúde da Família.

O resultado mostra que a maior parte dos entrevistados reside com companheira, destes 89,7\% consideram esse relacionamento como bom ou ótimo. Constatou-se que o tema é de importante relevância para a vida dos idosos e que a sexualidade continua presente na vida dos homens maiores de 60 anos. O que é completamente normal fisiologicamente para homens e mulheres idosas.

Vivenciar a sexualidade para o idoso tem múltiplas formas e dimensões, sendo plural, devendo ser vista não só pelo próprio idoso, mas pela sua família e sociedade da qual faz parte e que a Estratégia Saúde da Família completa este cotidiano.

O quarto artigo trata-se de uma pesquisa descritiva exploratória, em que é utilizada a teoria das Representações Sociais. Esta teoria possibilita diversas alternativas para compreender os processos e mecanismos construídos pelos sujeitos sociais em suas relações cotidianas, ou seja, na prática do dia a dia. Foi desenvolvido na Unidade Básica de Saúde da Família Maracanaú-CE, Brasil com 30 idosos.

Tem como objetivo conhecer as representações sociais a respeito da sexualidade do idoso. Na entrevista foi colocada para os sujeitos da pesquisa a palavra "Sexualidade" mediante este indutor foram várias interpretações mediante o tema. No total foram aproximadamente 150 palavras, muitas diferentes uma das outras, mostrando uma diversidade de opiniões.

Mas como se esperava as palavras: amor, carinho respeito eram sinalizadas como elementos centrais da representação social da sexualidade da terceira idade e as demais palavras como: sexo, companheirismo, compreensão e convivência eram elementos intercessores da representação do grupo estudado. Consequentemente conclui-se que o sexo não representa o aspecto mais importante para o idoso, mas que os valores, atitudes necessitam ser mais trabalhados em todos os espaços, despertando os interesses dos profissionais em relação a esta temática. 
Neste texto após as análises concluiu-se que os elementos centrais que permeavam os discursos eram: amor, respeito e carinho, pois estes elementos estruturam e organizam a representação social da sexualidade do idoso na pesquisa.

$\mathrm{O}$ artigo cinco trata-se de um programa de estudo em Sexualidade (ProSex) do Instituto de Psiquiatria do Hospital das Clínicas da Faculdade de Medicina da Universidade de São Paulo. Esta pesquisa revela que os avanços da medicina e da educação promovem além de melhor expectativa de vida recursos para a preservação da vida sexual mesmo com a idade avançada.

Diante do publicado o objetivo do texto é debater sobre os conflitos das mudanças psicossociais características do processo de envelhecimento sobre a função sexual feminina, mas traz que quem pratica muito sexo na vida adulta, o faz na velhice com mais frequência.

Ressaltam que os preliminares antes do sexo as entrevistadas relatam que continuam com a mesma frequência na velhice. A atividade depois da penetração vaginal menos frequente; as carícias preliminares o mais citado como prática sexual é o sexo oral. O texto conclui que as atividades sexuais na terceira idade são realizadas com "toque, carícias sem cópula e masturbação e por último coito. A saúde aumenta a expectativa da vida sexual ativa e saudável".

Finalizando, a produção seis trata de uma pesquisa descritiva exploratória, a qual foi necessária à abordagem qualitativa, pois a base da pesquisa se pautou na observação participante na qual o entrevistador atua juntamente com os entrevistados, mas não foi descartada a entrevista semiestruturada. A entrevista foi realizada pela Equipe da Estratégia Saúde da Família com os profissionais que faziam parte da equipe. Um trabalho coletivo entre médicos e enfermeiros em um total de doze profissionais.

Teve como objetivo verificar como médicos e enfermeiros desenvolvia sua prática cotidiana na Estratégia Saúde da Família no que se alude aos aspectos da sexualidade em idosos. Como resultado final foram detectados que as significações atribuídas pelos profissionais à sexualidade na terceira idade eram de difícil acesso, pois as pessoas idosas se envergonhavam inicialmente ao falar sobre sua sexualidade.

Chegou-se à conclusão que o tema era abordado depois de algumas reuniões e assim obter a confiança dos envolvidos nas consultas, embora fundamental no contexto da unidade de saúde, sendo tema de grande importância na atualidade mediante os agravos em saúde recorrente principalmente em idosos/as. Quando falamos das doenças sexualmente 
transmissíveis os idosos ficam salientes e embaraçados, então se faz necessário um elo de confiança antes de começar a abordagem e trabalha-las.

\section{Discussão}

As contribuições obtidas mediante os discursos, ainda ressaltam a escassez de ações voltada para essa temática nas unidades de saúde, sinalizando fragilidade e uma lacuna no que diz respeito à atenção integral a saúde do idoso.

Após a reflexão dos artigos elencados na tabela dos teóricos que dissertam sobre o tema Sexualidade em pessoas Idosas pode-se após análise e discussão em pares chegar a algumas conclusões: O preconceito quanto à sexualidade da pessoa idosa mesmo na contemporaneidade é muito grande, pois ainda pensam que o idoso é assexuado; $O$ gênero feminino tem dificuldade em exteriorizar seu entendimento sobre a sexualidade; $\mathrm{O}$ sexo em pessoas idosas não se resume apenas a cópula, mas sim a todo o processo de carinhos, carícias, toques, beijos, afagos e principalmente o companheirismo.

De acordo com o material analisado, pode-se comprovar cientificamente que diversos fatores sociais interferem na sexualidade do indivíduo idoso. Para tanto, o terceiro artigo intitulado Percepção de mulheres idosas sobre sua sexualidade: implicações de gênero no cuidado de enfermagem traz como exemplo de fatores sociais que interferem na sexualidade, uma abordagem bastante clara quanto ao fator sentimental, mostrando o quanto as mulheres possuem dificuldade para exteriorizar seu entendimento sobre sexualidade frente às conversas com outros indivíduos de um mesmo gênero. Na mesma linha encontra-se o artigo sexto aborda o relacionamento grupal deixando clara a interferência dos fatores sociais representados por profissionais da saúde quando no momento das entrevistas, os idosos mostram-se embaraçados, necessitando de um elo de confiança no momento da abordagem sobre o tema.

Ainda no processo de discussão dos artigos supracitados, pode-se destacar enquanto teorias que refere a sexualidade na terceira idade, mais precisamente levando em consideração as suas representações sociais, Queiroz et. all deixa claro que no amor e sexo deve haver respeito mútuo, embutido com uma dose de carinho na tentativa de reestruturar o processo sexual em pessoas da terceira idade. Em contra partida a esse pensamento, Coelho et all afirma em seu artigo que mesmo havendo comprometimento, as mulheres sentem dificuldade em 
expressar seus sentimentos. Ainda nesta análise Junqueira ao falar da sexualidade em mulheres idosas frente ao trabalho realizado com a equipe multiprofissional, ele deixa claro que deve identificar peculiaridades na atividade sexual desse grupo analisado, com isso ele quer afirmar o trabalho de Coelho, dizendo que realmente as mulheres mesmo em situação amorosa compartilhada devem ser analisadas, pois existe a possibilidade da dificuldade em expressar-se sexualmente.

\section{Considerações Finais}

O modo como os profissionais abordaram as questões de sexualidade de idosos ainda centravam-se no discurso da dificuldade de manejar essa temática dentro das unidades de saúde, por fatores relacionados ao preconceito do próprio corpo e aos mitos que circundam esse assunto.

As analises efetuadas com o material obtido permitiram apontar amor, respeito e carinho como elementos centrais que estruturam e organizam a representação social da sexualidade na terceira idade construída pelo grupo estudado com bases na Teoria das Representações Sociais. O sexo apareceu enquanto elemento periférico obtendo alta frequência de evocações, porem não enunciados prontamente, denotando não representar o aspecto mais importante para o idoso.

O quantitativo reduzido de estudos reforça a necessidade de maiores pesquisas relacionadas as representações sociais da sexualidade pelo idoso. Observou-se, também, no decorrer do estudo, um numero pequeno de trabalhos científicos relacionados ao assunto, indicando urgência de estudos mais densos sobre sexualidade na terceira idade, em uma perspectiva ampliada. Aspectos relacionados a sexualidade dos idosos devem ser melhor trabalhados na academia, fomentando aos profissionais refletirem sobre os mecanismos que geram valores e atitudes em relação a temática.

Acredito que os objetivos da pesquisa foram alcançados, sabendo que estudar a sexualidade da pessoa idosa reflete um grande desafio. O tema é bastante complexo, pois tem diversas dimensões e com um público saliente, com medo de se expor, de falar sobre seus desejos secretos. Os idosos refletem uma educação repressora e muito rígida, o que torna compreensível o silêncio principalmente quando o assunto é sexo. 
A dificuldade de encontrar subsídios teóricos foi ampla, considerando a escassa literatura sobre o tema. Discorrer, investigar e orientar a pessoa idosa sobre sua sexualidade torna-se bastante complexo, partindo do pressuposto de que se deve respeitar a história de vida de cada um, seu contexto e seus paradigmas. O corpo idoso sofre as transformações do tempo vivenciado.

O envelhecimento biológico é característico, muitas vezes os autores colocam o desgaste das relações com as parceiras, o social, a questão econômica, a própria vida com os filhos e netos, como interferência no prazer no momento da relação sexual. Tais limitações literárias podem ser exploradas a partir de novas investigações assim como no desenvolvimento de ações dentro das unidades de saúde junto com os profissionais sobre a temática "sexualidade na terceira idade", com o intuito de tornar o tema mais difundido e qualificado entre os profissionais que compõem a atenção primária em saúde e consequente melhoria a saúde coletiva.

Conclui-se que os relatos dos teóricos foram ricos e podem ser contemplados para melhorar a prática cotidiana dos que cuidam e também dos próprios idosos. Saber que os idosos se completam com o desenvolvimento da sexualidade compartilhada e ladeada de carícias, companheirismo, amor, cuidados que atitudes favoráveis trazem bem estar e podem envelhecer com mais ternura e saúde; faz com que a esperança de uma longevidade saudável com a sexualidade presente não esteja tão distante como a sociedade pensa, e, sim presente de forma velada.

\section{Referências}

BRASIL. Estatuto do Idoso. Ministério da Saúde. 2. ed. rev. Brasília: Ministério da Saúde, 2006.

. Política Nacional do Idoso. Lei 8842/94. . Brasília: Ministério da Saúde, 2004. . Constituição Federal Brasileira. 1988.

CEZAR, A K; AIRES, M; PAZ, A A. Prevenção de doenças sexualmente transmissíveis na visão de idosos de uma Estratégia da Saúde da Família. Rev. Bras. Enferm. Brasília, v. 65, n. 5, p. $745-750$, out. 2012. 
COELHO, M.S. F et al. Percepção de mulheres idosas sobre sexualidade: implicações de gênero e no cuidado de enfermagem. Rio de Janeiro: Vozes, 2010.

COFEN. Código de Ética de Enfermagem. Brasília, 2016.

CUNHA, L. M. et al. Vovô e vovó também amam: sexualidade na terceira idade. Rev. Mineira de Enfermagem. Vol. 19, № 4, out/dez, Belo Horizonte, 2015.

FLEURY, H. J.; ABDO, C.H.N. Sexualidade da mulher idosa. Diagn Tratamento. São Paulo, 2015; 20 (3):117-20.

JESUS. P. B. R. de. Et al. A teoria do cuidado transpessoal de Jean Watson: Evidências científicas na literatura de enfermagem. Seminário Nacional de Pesquisa em Enfermagem. Junho, 2013.

LIMA E SILVA, V.X. et al. Satisfação sexual entre homens idosos usuarios da atenção primária. Rev. Saúde e Sociedade, vol. 21, nº 1, Jan. São Paulo, 2012.

MENDES, K. D. L.; SILVEIRA, R. C. C. P.; GALVÃO, C. M. Revisão integrativa: método de pesquisa para a incorporação de evidências na saúde e na enfermagem. Texto \& Contexto Enfermagem. Florianópolis, v.17, n.4, p.758-764, 2008.

MORAES, J.K et al. Companherismo e sexualidade de casais na melhor idade: cuidando do casal idoso. Rev. Bras. Geriatr. Gerontol. Rio De Janeiro, 2011.

ORGANIZAÇÃO MUNDIAL DE SAÚDE (OMS). Envelhecimento Saudável. 2015. Disponível em < http://www.who.int/about/licensing/copyright_form/en/index.html>. Acesso em 23.09.2018.

QUEIROZ, M. A. C. et al. Representações sociais da sexualidade entre idosos. Rev. Bras. Enferm. vol.68 No .4. Brasília July/Aug. 2015.

WELLMAN NS: Aging at home: more research on nutrition and independence, please. Am F ClinNut. 91:1151, 2010.

\section{Como citar este artigo (Formato ABNT):}

GOMES, Renara Meira; CIDREIRA, Joserlane M.; SANTOS, Maria da Conceição Q. dos ; BASTOS, Norma Lopes de M. V.; SANTOS, Kay A.; SANTOS, Maria Lucia Q. dos. Sexualidade na terceira idade: as representações sobre sexo. Id on Line Rev.Mult. Psic., 2018, vol.12, n.40, p.939-955. ISSN: 1981-1179.

Recebido: 26/05/2018

Aceito 28/05/2018 